\title{
HIV/AIDS community information outreach program (ACIOP): A landmark NIH conference and an enduring NLM role in meeting the affected community's need for information access
}

\author{
Gale A. Dutcher* \\ U.S. National Library of Medicine (retired), USA
}

\begin{abstract}
In June 1993, the National Library of Medicine (NLM) joined with the National Institutes of Health's (NIH) Office of AIDS Research (OAR), and the National Institute of Allergy and Infectious Diseases (NIAID) to host a conference at a pivotal time in the HIV/AIDS epidemic to understand better the information needs of five major constituency groups: clinical researchers; clinical providers; news media and the public; patients; and the affected community. NLM's director, Donald A.B. Lindberg M.D., and staff sought to identify new program possibilities benefitting from the input of current and potential users of the Library's information services. Conference recommendations led to a key NLM policy change providing cost-free access to all AIDS data, and the establishment of the HIV/AIDS community information outreach program (ACIOP), which enabled new partnerships with local community-based organizations serving the affected community. Uniquely funded and long running, more than 300 ACIOP projects have been supported to-date. These projects have improved awareness and use of national HIV/AIDS information resources; enhanced information seeking skills; developed locally generated information resources; and enhanced the capacity of community-based organizations to use new information and computer technologies providing access to essential information resources and services.
\end{abstract}

Keywords: Donald A.B. Lindberg M.D., U.S. National Library of Medicine, U.S. National Institutes of Health, HIV/AIDS community information outreach program, HIV/AIDS information services conference, community-based outreach

\section{Introduction}

The first cases of what would later become known as Acquired Immunodeficiency Syndrome (AIDS) were reported in the United States by the Centers for Disease Control in June 1981 [1]. This was quickly followed by reports of previously healthy young homosexual men becoming infected with Pneumocystis pneumonia, a type of pneumonia that almost never affects people with intact immune systems, as well as Kaposi's Sarcoma, usually found in older men in Mediterranean countries [2].

\footnotetext{
*E-mail: gad695@yahoo.com.
} 


\subsection{Early responses}

The primary communities affected by what would become known as the AIDS pandemic were gay white men and Haitians. While this changed and broadened over time, AIDS' initial impact on marginalized communities was accompanied by a highly negative public response. The initial name for this disease was GRID-gay-related immunologic syndrome. Along with an initially high mortality, it was characterized by homophobia, discrimination, and stigma against those diagnosed with the disease.

There continued to be widespread fear and hostility to people with AIDS and the human immunodeficiency virus (HIV) that causes AIDS which drove the political and social responses to this disease. With mainstream medical, social and human services organizations so fearful and reluctant to provide care and support services to people living with HIV and AIDS, the communities most impacted created organizations to take care of their own members. These community-based AIDS service organizations were founded to support and care for people with AIDS primarily because of homophobia and distrust of the government and public health agencies as well as the slowness of these agencies to respond to what was seen as a crisis from within the affected community. They also served as advocates for these communities.

\section{National Library of Medicine's (NLM) involvement in AIDS}

Information about AIDS, HIV, research, transmission, and care became critically important. The Health Omnibus Programs Extension (HOPE) Act of 1988 (PL 100-607) included a section that provided funding for AIDS-related education, prevention, research, and testing. The National Library of Medicine (NLM) was prescient in its creation of bibliographic tools related to AIDS. Initially it created printed bibliographies and then AIDSLINE, an online database. Donald A.B. Lindberg M.D., Director of the National Library of Medicine made the official determination that this satisfied the legislative requirement to establish a "data bank of information on the results of AIDS research".

The urgency of the situation led to significantly increased funding to the National Institutes of Health (NIH) specifically targeting work relating to the AIDS pandemic. The NIH Office of AIDS Research (OAR) was responsible for the allocations to each institute for their AIDS-related activities. Dr Lindberg was very firm that he only wanted NLM to accept the additional funding if there were worthwhile new programs NLM could do that would add to the improvement of the situation and solicited input from staff for their ideas. Besides continuing and expanding NLM's traditional role of collecting books and journals, indexing the research literature, and making AIDSLINE and other databases available, Dr Lindberg and Library staff determined that it needed more input from users and potential users to understand their information needs.

\section{HIV/AIDS information services conference}

To obtain this information from the full gamut of users and potential users, NLM collaborated with the NIH's OAR and the National Institute of Allergy and Infectious Diseases (NIAID) to hold a conference on behalf of NIH to identify the information needs of relevant constituent groups. The planning committee was chaired by Elliot R. Siegel Ph.D., NLM Associate Director for Health Information Programs Development, and consisted also of representatives from external organizations such as the National Association of People with AIDS, community-based organizations, public health agencies, and 
NIH staff. Gale A. Dutcher MS MLS, Special Assistant to the NLM Associate Director, Division of Specialized Information Services assumed day-to-day responsibility for organizing the conference.

The first step was to identify the potential audiences for NIH's information. Initially they were basic science researchers, clinical researchers, clinical care providers, general public, and communitybased organizations (CBOs). Preliminary research, including interviews with basic scientists, led to the elimination of basic scientists from the conference agenda as the feedback that was received showed that they had sufficient institutional access to the information they needed to advance their work. This was the type of information that NLM had been effectively providing for over 150 years.

The NLM/NIH HIV/AIDS information services conference took place in June 1993. It was organized around the HIV/AIDS information needs of five major constituency groups: clinical researchers; medical, dental, and nursing providers; allied health care providers; news media and the public; and patients and the affected community [3].

Keynote addresses by Dr Lindberg; Anthony Fauci M.D., Director, National Institute of Allergy, and Infectious Diseases; June Osborne M.D., Chair, National Commission on AIDS; and Debra FrazerHowze, Black Leadership Commission on AIDS provided big-picture perspectives to the constituency group panels and the audience. Each panel represented a specific constituency group and was given a scenario to guide their discussion. The result of the panel discussions and audience participation was more than 40 recommendations to NIH related to information needs and access.

The planning group as well as the conference participants were diverse and included good representation from all those impacted by AIDS - researchers, policy makers, information providers, as the affected community. It was the first opportunity for many NLM staff to work with people infected with HIV or who were active in that community. While Dr Lindberg was not at all concerned by this, some of the NLM staff were worried about seating arrangements and being close to someone who might be infected.

\subsection{Major conference recommendations}

The panel discussions resulted in a large number of recommendations that would help meet the needs of the various constituency groups.

The clinical researchers' recommendations centered around immediate access to the results of clinical trials regardless of where they were being conducted, and increased transparency of the most current information from important conferences. They also recommended more information for patients and health consumers.

Medical, dental, and nursing providers obtain their information through differing routes than the clinical researchers and they may not have the time, access, or expertise to obtain and synthesize reports from the scientific literature. They sought synthesized, integrated information to directly support patient care. The lack of access to information was most profound for practitioners working in more remote areas.

Allied healthcare providers, including case managers, social workers, nutritionists, and various types of therapists, are often the provider most frequently seen by people with AIDS or HIV. They work in various settings and may not be based in a resource-rich institution such as a medical center. Their needs were clearly related to access to existing systems for information dissemination and the availability of the type of information they can use - relevant topics, particularly substance use, psychosocial issues, and alternative treatment, and at the appropriate technical level.

The media are the main conduit that NIH used to transmit information to the general public. However, a surprising finding was that the media does not see its primary role as educational. They did emphasize their need to have better access to the scientists to obtain the information needed for their reporting. The 
panel also encouraged NIH to use other mechanisms to reach the public and not rely only on traditional media.

The importance of accurate and current information is critical for patients and the affected community. Because of the stigma, prejudice and discrimination shown to people with HIV and AIDS, this group organized to take care of themselves and their own community. They wanted accurate information available where they spent time and in formats that were useful. They wanted it to be available to their care providers as well as to the affected community. Electronic information services, which were seen to have the potential to get information out to the community quickly, were not readily available for many different reasons, including cost, complexity, and access to technology.

\subsection{NLM's initial response: Cost free access}

In January 1994, Dr Lindberg took the major step of announcing that NLM's AIDS-related databases were available to all free of charge [4]. This was responsive to recommendations from several of the panels and would be of assistance to health professionals not affiliated with institutions providing access to NLM's resources. It would particularly help community-based organizations providing services to the affected community. This was the first time that NLM made its databases available free of charge to anyone who registered and obtained an access code. Although the pre-web search system in use at that time was complex, it did provide access to those who otherwise would not be able to afford to use the most up-todate information available through NLM. Beyond this, providing free access gave NLM experience with opening access, which took place in 1997.

\section{New NLM initiative launched: HIV/AIDS community information outreach program (ACIOP)}

It was clear from the conference discussions that people with and affected by HIV/AIDS wanted access to timely and accurate information. It was also clear that many members of this group and the communitybased AIDS service organizations that had arisen in the earliest years of the AIDS epidemic did not have access to or the ability to access electronic information resources.

To provide support to these organizations, NLM issued a request for proposals (RFP) for AIDS community information outreach projects in May of 1994. This was NLM's first significant outreach program for community organizations. The goals of this competitive funding opportunity were to support access to and the use of quality relevant information, including training, equipment, and connectivity. Further, the conference recommended that the public library system be utilized to provide assistance in getting accurate, timely information to the public.

In what turned out to be the first of many annual rounds of funding, a total of nearly $\$ 500,000$ was awarded to 19 projects. The goal was to improve access to HIV/AIDS information for health professionals, patients, the affected community, caregivers, and the general public; encourage partnerships and community-focused activities; and promote awareness and use of technology applications for improved information access. The selected projects addressed one or more of the following:

- providing or improving access to electronic HIV/AIDS-related information resources by organizations or by the clients they serve, including the purchase of equipment and telecommunications services and creating a computer facility in a CBO.

- providing or obtaining training to develop skills to access or use HIV/AIDS-related information, including using the Internet and critical assessment of the quality of retrieved information. 
- developing specific educational or information materials, such as culturally appropriate or language specific tools.

- providing access to HIV/AIDS-related documents, for example, developing connections with local health sciences libraries to obtain use of their collections.

NLM designed the AIDS community outreach program to improve access to HIV/AIDS-related information by CBOs, public libraries, people living with and affected by HIV/AIDS, and the general public. In response to guidance from its constituents in the HIV/AIDS service community, NLM's role has been to specify the program objectives and the types of activities it would support. It respected the community's expertise in designing and proposing projects most likely to be effective in their communities. NLM's supportive role has fostered the development of projects that are "owned" by their communities, and helped to create productive working relationships between NLM and information providers.

\subsection{ACIOP over time}

The first group of institutions receiving awards was diverse. It included community organizations (e.g., Critical Path AIDS Project, Santa Cruz AIDS Project), departments of health (e.g., Seattle-King County Department of Public Health), libraries (e.g., Kansas City Public Library), and academic institutions (e.g., Eastern Virginia Medical School) [5].

The early projects that NLM funded generally focused on basic services. Few of the organizations or their clients were in a position to use advanced technology. For example, the New York Public Library projects $(1994,1996)$ expanded branch and reference library collections to include HIV/AIDS educational materials. The NYPL-Staten Island project (1994) acquired books in both English and Spanish, pamphlets from a variety of sources, videos, and newsletters and magazines. AEGIS (1995) was one of the first projects to use the web. Prior to NLM funding they ran a dial-up BBS (bulletin board) service over telephone lines. They migrated to a listserv with the funding. The growing demand for listservs suggests that email was increasingly available to consumers of HIV/AIDS information. AEGIS (1995) reports that its FTP server "isn't used much because of the Web, except by people from very remote sites with limited tech use ... who download info and recreate databases in their countries". According to AEGIS (1995), the "Web has changed everything".

Several projects received funding over multiple years. One notable example was Philadelphia Fight. Two components of that organization received funding in 1994-Critical Path AIDS and the AIDS Information Network (AIDS Library). They or another component of Philadelphia FIGHT received funding in many of the following years. An expansion of the AIDS Library and the Critical Path Project, the Critical Path Learning Center at Philadelphia FIGHT is an educational commons and stigma-free space devoted to the intersection of health and literacy for the digital age, received funding. They made information access central to their mission. Over the years, NLM funded the AIDS Library to set up computers for public access in their facility, an educational program called Project TEACH, and the Critical Path Project to develop electronic resources and websites.

Over time, the demographics of those most affected by HIV/AIDS changed from predominately gay White men to communities of color, including both men and women. This led to changes in the organizations receiving funding and the populations they served. In addition, the later projects took advantage of newer technology, including sophisticated use of social media, audio and video to develop locally or population-relevant resources. HIV PrEP Navigator resources and dissemination strategy development was also supported and included tailored web-based videos and educational modules, text 
messages or email messaging campaigns, as well as culturally and language specific fact sheets, and user guides tailored to meet the needs of the organization's clients or communities.

Another example is Black Girl Health which helps minority women make informed decisions about their health. They run a national social media campaign using Facebook and Instagram to increase awareness about HIV prevention, specifically pre-exposure prophylaxis (PrEP) and post-exposure prophylaxis (PEP). By connecting Black women to the National Library of Medicine (NLM) HIV/AIDS resources, educating them about PEP and PrEP, offering them support, and teaching them how to transfer this knowledge to their own self-care, Black Girl Health educates African American women to make better informed decisions regarding their health. BGH also collaborated with NLM to develope a YouTube video highlighting the 2016 awardees whose projects incorporated the use of new information technologies [6].

\section{Successive evaluations of the ACIOP}

This program is more than 25 years old and has undergone periodic reviews, assessments and formal evaluations during that time period, which has led to modifications of the program to keep it useful, relevant and impactful.

The first review of NLM's program covered 1994-1997 (unpublished internal document). It was essential to conduct this early review since the program was so new and different from anything that NLM had done previously. This unpublished review examined the reported accomplishments of the projects. It found that they could be grouped as follows:

- Awareness and use of HIV/AIDS information resources

- Improving access to educational materials

- Improving access to the internet

- Improving information skills

- Developing new resources

- Building organizational capacity to provide information services

- Developing computer infrastructure

- Fostering partnerships and collaborations

NLM learned valuable lessons from this first set of projects which could then be applied to future program efforts. The staff of community-based organizations required a great deal of training to learn how to use electronic resources and to incorporate this information into their daily tasks. This was very early in the Internet era and staff were not using the Internet or telecommunications in their daily lives. Although public library staff were more accustomed to searching for information, they required extensive training in searching NLM's databases and in accessing and searching the Internet before they were prepared to assist the public. One of the most important findings was that community-based organizations required more than one funding period to reach the point of providing direct access to electronic resources for their clients, or to otherwise bring their projects to a satisfactory point. NLM also recognized the importance of good leadership and in having a champion within the organization. This is critical in community organizations since there is often high staff turnover, extensive use of volunteers, and loss of important staff due to the impact of the disease. 
Even during the relatively brief time covered in this review, the epidemic and the Internet changed significantly, and this impacted the community organizations. The Internet and the web became much more widely available and used, the demographics of the affected community shifted with increasing numbers of minority and lower income individuals becoming infected, and finally, there was an increasing need for more information about general health as people started living longer.

A later look at the program showed the impact and continued need for funding [7]. Through 2005, NLM made more than 190 awards and incorporated programmatic changes based on reviews and analysis of report submissions from the organizations. For example, the initial funding amount in 1994 was $\$ 25,000$. Later, funding levels were raised to $\$ 50,000$ for standard awards and an express category for $\$ 10,000$ was added which supported smaller scale projects and required reduced application requirements. A qualitative assessment of projects funded in 2002 (most of which were carried out over a 2-year period) found that increased access, use and knowledge of HIV information significantly impacted the clients' communication, improving their ability to ask knowledgeable questions. For many of the organizations, making technology and access to HIV information available in disadvantaged communities filled a significant gap in those areas and provided information and tools that would otherwise not be available. It also extended the reach of the organization beyond their immediate community. Anecdotes from users of some of these services have credited that the access provided was "keeping them alive".

This assessment repeated the findings of the earlier review that a strong, committed project leader was an essential component for success. Further, the staff turnover, particularly in the smaller communitybased organizations, was also a problem in managing projects and resulting in the loss of institutional memory and knowledge.

In 2012, a major external program evaluation was undertaken to determine the performance and impact of the AIDS community information outreach program (ACIOP). This systematic and detailed analysis was carried out by researchers from Columbia University in conjunction with the ACIOP staff at NLM [8].

It was important to review the program given the substantial level of resources NLM invested and in recognition of the changing environment over the approximately 20 years of the program. The researchers analyzed a sample of project reports and conducted structured interviews of a number of projects. Since 1994, the Internet and web have become pervasive and more accessible, and social media had become one of the main communication tools, especially among younger people.

This evaluation found that, in general, planned project objectives were achieved and successful projects built on existing efforts. Most of the projects identified barriers to success and found ways to overcome them. Some of these barriers repeated the findings of earlier assessments and reviews, such as staff changes leading to gaps in project management. The most significant problem or barrier identified was the lack of evaluation capacity in community organizations. We found that few community organizations had the staffing or training to know how to evaluate their projects.

One recommendation from this evaluation was that NLM provide more guidance and support to the community organizations to enable them to do more effective evaluations, including needs assessments and developing measurable objectives. NLM carried out a pilot project which involved helping a group of organizations to include evaluation in their ACIOP projects [9]. Based on lessons learned from this pilot, NLM modified the proposal submission and evaluation criteria for funding to include a required logic model so that evaluation planning was considered early in the program development process. NLM was able to determine the evaluation capacity of each proposer prior to award. Post award, NLM supported the organizations with evaluation consultation to ensure that their projects aligned with their logic model. This effort increased the successful implementation and evaluation of ACIOP projects and enhanced the evaluation capacity for low-resource awardees. 


\section{An innovative model for community-based outreach}

Initial conception and direction of the ACIOP was under the leadership of Gale Dutcher who later became Chef of the SIS's Office of Outreach and Special Populations. She was followed by her associate Nicole Scott whose very capable management of the ACIOP began in 2007; and Andrew Plumer assumed day-to-day responsibility in 2014. Ms. Scott was instrumental in guiding ACIOP's several transitions, a comprehensive formal evaluation, and an experimental effort at capacity building enabling awardees to undertake their own project evaluations with the assistance of an evaluation consultant provided by NLM.

The ACIOP was a risky and unusual undertaking for an NIH Institute. Funding was provided in the form of targeted small contracts rather than grants as the Intramural administrative status of the NLM's division of specialized information services is not authorized to award grants. Moreover, the contracts were structured for community organizations that were unlikely to have the staff expertise to compete for standard NIH research grants and were most likely unfamiliar with the federal contracting process. Dr Lindberg and NLM staff felt strongly that the critical nature of the AIDS epidemic justified this unusual funding approach.

NLM has funded over 300 ACIOP projects. The periodic reviews have led to program modifications to enhance the program, determine the impact of the ACIOP effort, and ensure ACIOP remains relevant and responsive to current community needs. Project funding has fluctuated over time and reporting has improved, as NLM created more structured reporting and evaluation criteria to determine the impact of the projects. As the epidemic changed and technology became more ubiquitous, the emphasis of the projects also changed, as did the needs of the organizations. One thing remained true throughout the entire timethe importance of meeting the needs of the local community and their local authority of the projects. All in all, using NLM's quality information resources was essential at the local and national level.

ACIOP awardees were community organizations mostly serving minority, disadvantaged or marginalized populations. Over the years, NLM has established partnerships and built relationships with communities where their lack of trust may have inhibited NLM's direct reach and engagement with diverse populations that need HIV information the most. By working with organizations and identifying "ambassadors" and "champions" in communities that have already developed trusted relationships with their clients and community members, NLM has been able to ensure that ALL individuals have access to high quality, accurate and authoritative information in settings that are comfortable for them.

The AIDS community information outreach program continues to be relevant and beneficial both to the HIV/AIDS community and to NLM. It remains a very important component of NLM's work with communities and community organizations. Lessons learned over time have proven relevant not only to this one program, but to information outreach in general, whether directly from NLM or through the Network of the National Library of Medicine (NNLM) [10]. The success of NLM's community-based outreach can be attributed to Dr Lindberg's leadership and his staff's willingness to break away from what was considered the "normal" established audiences and partnerships as initially identified in the then-groundbreaking 1989 DeBakey Outreach Panel Report [11]. NLM outreach broke new ground and progressed in new directions with the evolution of the AIDS community information outreach program.

\section{References}

[1] Centers for Disease Control. Pneumocystis pneumonia-Los Angeles, MMWR 30(21) (1981), 1-3. [Internet] [cited 2021 July 9] Available from: https://www.cdc.gov/mmwr/preview/mmwrhtml/june_5.htm. 
[2] Centers for Disease Control. A cluster of Kaposi's Sarcoma and Pneumocystis carinii Pneumonia among homosexual male residents of Los Angeles and Orange Counties, California, MMWR 31(23) (1982), 305-307. [Internet] [cited 2021 July 9] Available from: https://stacks.cdc.gov/view/cdc/35035.

[3] National Institutes of Health. Office of AIDS Research. National Library of Medicine. Information services for HIV/AIDS: recommendations to the NIH: Report of a Conference. U.S. Dept of Health and Human Services, Bethesda, MD, 1994 [Internet] [cited 2021 July 9]. 71 p. Available from: https://www.google.com/books/edition/_/s64TAQAAMAAJ?gbpv=1.

[4] NLM offers online HIV/AIDS information services at no charge. NLM News 1994 January-February; 49(1). [Internet] [cited 2021 July 9]. Available from: https://www.nlm.nih.gov/archive/20040422/pubs/nlmnews/janfeb94.html.

[5] National Library of Medicine. HIV/AIDS community outreach information program (ACIOP). Past funded projects: 1994 2019. pp. 1-99 [Internet] [cited 2021 July 9]. Available from: https://www.nlm.nih.gov/oet/partnerships/ACIOP_Past Projects.pdf.

[6] Black girl health. YouTube video highlighting 2016 ACIOP awardees. https://www.youtube.com/watch?v=U6DkJ5yPSCA \&list=PLCA76BACD15A0F1D0.

[7] N.C. Dancy and G. Dutcher, HIV/AIDS information outreach: A community-based approach, J Med Libr Assoc 95(3) (2007), 323-329.

[8] N.C. Dancy, M.L. Rockoff, G.A. Dutcher, A. Keselman, R. Schnall, E.R. Siegel et al., Empowering patients and community online: Evaluation of the AIDS community information outreach program, Information Services and Use 34(1,2) $(2014)$, $109-148$.

[9] N. Dancy-Scott, A. Williams-Livingston, A. Plumer, G.A. Dutcher and E.R. Siegel, Enhancing the capacity of community organizations to evaluate HIV/AIDS information outreach: A pilot experiment in expert consultation, Information Services and Use 36(3, 4) (2016), 217-230.

[10] J.P. Shipman, C.M. Burroughs and N. Rambo, NLN's library network: A force for outreach. in: Transforming Biomedical Informatics and Health Information Access: Don Lindberg and the U.S. National Library of Medicine, B.L. Humphreys, R.A. Logan, R.A. Miller and E.R. Siegel (eds), IOS Press, Amsterdam, 2021.

[11] National Library of Medicine (US). Board of Regents. Improving health professionals' access to information. [Internet]. U.S. Department of Health and Human Services, National Institutes of Health, Bethesda, MD, 1989 [cited 2021 July 9]. 28 p. Available from: https://collections.nlm.nih.gov/ext/kirtasbse/8912965/PDF/8912965.pdf. 